Article

\title{
Effects of a Reduced Effective Active Region Volume on Wavelength-Dependent Efficiency Droop of InGaN-Based Light-Emitting Diodes
}

\author{
Panpan $\mathrm{Li}^{1,2,+}$, Yongbing Zhao ${ }^{3,+}$, Xiaoyan $\mathrm{Yi}^{2}$ and Hongjian $\mathrm{Li}^{4, *}$ \\ 1 Department of Electrical and Computer Engineering, University of California, Santa Barbara, CA 93117, \\ USA; panpanli@ucsb.edu \\ 2 Semiconductor Lighting R\&D Center, Institute of Semiconductors, Chinese Academy of Sciences, \\ Beijing 100083, China; spring@semi.ac.cn \\ 3 School of Physics and Electronics, Yancheng Teachers University, Yancheng 224007, Jiangsu, China; \\ zhyb0515@163.com \\ 4 Materials Department, University of California, Santa Barbara, CA 93106, USA \\ * Correspondence: hongjianli@ucsb.edu; Tel.: +1-805-708-6766 \\ + These authors contributed equally to this work.
}

Received: 17 September 2018; Accepted: 29 October 2018; Published: 2 November 2018

check for updates

\begin{abstract}
In this study, wavelength-dependent efficiency droop phenomena in InGaN-based light-emitting diodes (LEDs) by a reduced effective active region volume were investigated. Different effective active region volumes can be extracted from theoretical fitting to the efficiency-versus-current curves of standard high efficiency InGaN near-ultraviolet, blue, and green LEDs. It has been found that the effective volume of the active region reduces more significantly with increasing emission wavelength, resulting in a lower onset-droop current density, as well as a more severe droop. Increasing the quantum well (QW) thickness to reduce carrier density is proposed as an effective way to alleviate the efficiency droop.
\end{abstract}

Keywords: InGaN; light-emitting diodes; efficiency droop; carrier recombination; carrier localization

\section{Introduction}

Internal quantum efficiency (IQE) in InGaN light-emitting diodes (LEDs) suffers a substantial decrease with increasing driven currents, leading to the so-called efficiency droop effect [1]. Until now, many different theories have been put forward to explain the origin of this experimental observation, such as Auger recombination [2-4], electron leakage [5,6], lack of hole injection [7-9], and carrier delocalization $[10,11]$. In addition, the efficiency droop in long wavelength InGaN LEDs becomes more severe as compared to the blue and the near-ultraviolet (NUV) LEDs [11]. Direct measurement of Auger electrons and clear correlation between the Auger current and droop suggest that the Auger process is the main cause of efficiency droop [4]. The conventional ABC model is widely employed to study carrier recombination dynamics in InGaN quantum wells (QWs). In this model, the efficiency equation can be expressed as IQE $=\mathrm{B} n^{2} /\left(\mathrm{A} n+\mathrm{B} n^{2}+\mathrm{C}^{3}\right)$, where $\mathrm{A}, \mathrm{B}$, and $\mathrm{C}$ represent Shockley-Read-Hall (SRH), radiative recombination, and Auger coefficients respectively [12-15]. The ABC model can explain non-thermal droop in InGaN-based LED structures in terms of Auger recombination, which agrees well with available observations $[2,13,14]$. However, the ABC model is criticized for oversimplified treatment of physical processes and some disagreements with a number of observations at high injection current densities [12,15]. 
IQE can be expressed in a first-order approximation as [15,16]:

$$
\mathrm{IQE}=V_{\text {active }} \mathrm{B} n^{2} /(I / q)
$$

where $V_{\text {active }}$ is physical volume of active region, B is the radiative recombination coefficient, $n$ is carrier density within active region, $I$ is current injected into active region, and $q$ is elementary charge. In many studies carriers are assumed to be uniformly distributed within InGaN QW [12-14]. Nevertheless, carriers are actually localized in the potential minima of In-rich InGaN clusters [12,17-20], leading to a smaller effective active region volume ( $\left.V_{\text {effective }}\right)$ than the physical $V_{\text {active. }}$ It has been estimated that the effective QW thickness of InGaN blue LEDs would be reduced to only $\sim 1.0 \mathrm{~nm}$ under a physical well thickness of $2.5-3.0 \mathrm{~nm}[17,21,22]$. Consequently, carrier density in the numerical calculation is much smaller than real values, resulting in extracted coefficients of $n^{3}$ $\left(\sim 10^{-9} \mathrm{~cm}^{6} \mathrm{~s}^{-1}\right)$ [12], one order larger than reported Auger coefficients $\left(\sim 10^{-30} \mathrm{~cm}^{6} \mathrm{~s}^{-1}\right)$ from the photoluminescence measurement [1] and the first principle calculation [2]. In our previous study, an effective volume ratio $\beta$ was introduced as $\beta=V_{\text {effective }} / V_{\text {active }}$ in the efficiency equation function to describe the effect of reduced effective active volume on the IQE droop [15]. In this study we present a comprehensive study of wavelength-dependent efficiency droop in InGaN LEDs with emission wavelengths centered from $400 \mathrm{~nm}$ to $525 \mathrm{~nm}$ by a reduced effective volume of the active region.

\section{Methodology}

The equilibrium carrier density within active region can be obtained by:

$$
n=\sqrt{\mathrm{IQE} \cdot I} / \sqrt{\mathrm{B} q V_{\text {effective }}}
$$

Then, we can get:

$$
n=\sqrt{\mathrm{IQE} \cdot I} / \sqrt{\mathrm{B} q V_{\text {active }} \beta}=n^{\prime} / \sqrt{\beta}
$$

where $n^{\prime}$ equals $\sqrt{\mathrm{IQE} \cdot \mathrm{I}} / \sqrt{\mathrm{B} q V_{\text {active }}}$, assuming that carriers uniformly distribute within the InGaN QW. IQE can be finally expressed as [16]:

$$
\mathrm{IQE}=\frac{\mathrm{B}\left(n^{\prime} / \sqrt{\beta}\right)^{2}}{\mathrm{~A}\left(n^{\prime} / \sqrt{\beta}\right)+\mathrm{B}\left(n^{\prime} / \sqrt{\beta}\right)^{2}+\mathrm{C}\left(n^{\prime} / \sqrt{\beta}\right)^{3}}
$$

Items with power higher than a third are not employed as the physics behind this are not clear. Dai et al. try to use high power items as the carrier leakage to explain asymmetry but this is in dispute as no experiments can prove it [23]. External quantum efficiency (EQE) can be obtained by:

$$
\mathrm{EQE}=\left(P_{\text {output }} / h v\right) /(I / q)
$$

where $P_{\text {output }}$ and $h v$ are output power and photonic energy. Light extraction efficiency (LEE) is assumed to be 0.8 due to enhancement of patterned sapphire substrates (PSS). Then IQE can be obtained by IQE $=$ EQE $/$ LEE.

\section{Experiments}

Highly efficient InGaN NUV, blue, and green LEDs with emission wavelengths at 400, 455, and $525 \mathrm{~nm}$ were grown by metal-organic chemical vapor deposition (MOCVD) and fabricated using standard mesa structure. InGaN LED epitaxy wafers were grown on 2-inch c-plane (0001) patterned sapphire substrates (PSS). LED structures were composed of a $3.0 \mu \mathrm{m}$ undoped GaN layer, a $3.0 \mu \mathrm{m}$ Si-doped $n$-GaN layer, InGaN/GaN multiple quantum wells (MQWs), a $20 \mathrm{~nm} p-\mathrm{Al}_{0.15} \mathrm{Ga}_{0.85} \mathrm{~N}$ electron blocking layer, and a $250 \mathrm{~nm} p$-GaN main layer. X-ray measurements indicate that indium composition is about $6 \%, 15 \%$, and 30\% for the InGaN NUV, blue, and green LEDs respectively [23]. High power LED chips with a size of $1 \times 1 \mathrm{~mm}^{2}$ were fabricated. Indium Tin Oxide (ITO) $(100 \mathrm{~nm}$ ) was firstly 
deposited on top of $p$-type GaN as an ohmic contact and current-spreading layer. An $n$-type GaN layer was exposed by inductively coupled plasma etching around $1.3 \mu \mathrm{m}$. An $n$-contact of Ti/Al/Ni/Au $(10 / 100 / 100 / 100 \mathrm{~nm})$ was deposited onto the $\mathrm{nGaN}$ and $\mathrm{Cr} / \mathrm{Pt} / \mathrm{Au}(25 / 20 / 500 \mathrm{~nm})$ layers were deposited as $p / n$ pads. A patterned design of metal electrodes with multiple-branches for the $p / n$ contacts were employed to avoid the current crowding effect [24]. LEDs were packaged with silica gel and output power was measured in an integrating sphere. Pulse trains with $10 \mu$ s duration and $1 \%$ duty cycle were used to avoid a self-heating effect.

\section{Results and Discussion}

Measurement results of IQE versus injection current density for the three InGaN LEDs are plotted as dots in Figure 1a-c, respectively. Green LEDs present a more severe IQE droop, as well as a lower onset-droop current density, as compared with NUV and blue LEDs. By fitting experimental data through Equation (3), the values of parameters are extracted, as shown in Figure 2. Without introducing a large value of Auger coefficient, accurate fitting results can be achieved. Extracted Auger coefficients for these three LEDs are in the range of $0.8-2 \times 10^{-30} \mathrm{~cm}^{6} \mathrm{~s}^{-1}$, which agree well with expectations from theoretical calculations $[2,25]$ and experimental measurements [1].

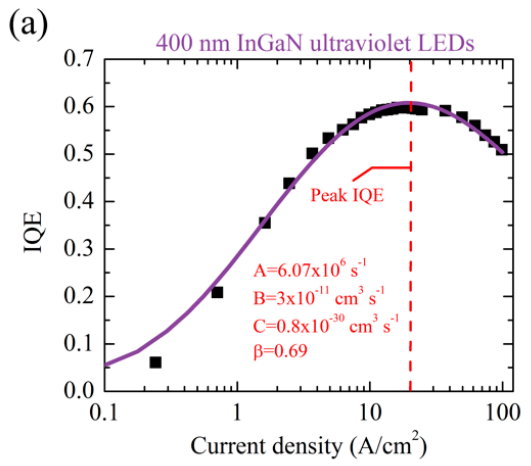

(b)

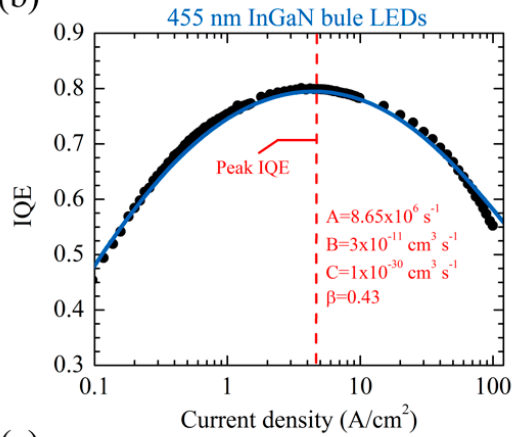

(c)

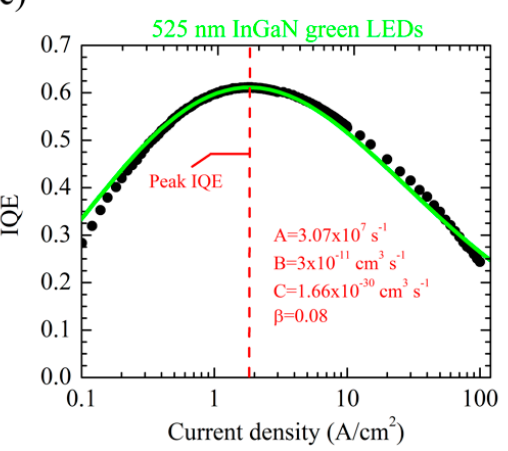

Figure 1. Fitting results to experimental internal quantum efficiency (IQE) versus current for InGaN (a) near-ultraviolet (NUV), (b) blue, and (c) green LEDs. 


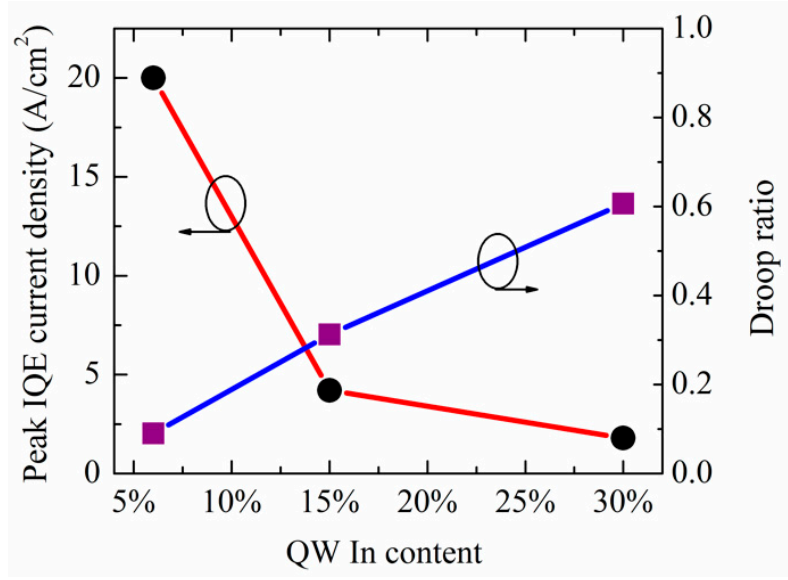

Figure 2. QW In composition-dependent onset-droop current density and droop ratio at $100 \mathrm{~A} / \mathrm{cm}^{2}$.

Droop ratio is defined as (Max_IQE-IQE)/Max_IQE, where Max_IQE represents peak IQE. The QW In composition-dependent onset-droop current density and droop ratio at $100 \mathrm{~A} / \mathrm{cm}^{2}$ are shown in Figure 2. With increasing emission wavelength, the onset-droop shifts towards a lower current density. Meanwhile, the droop ratio increases. As the QW indium content increases from 6 to $30 \%$, onset-droop current density reduces from 20 to $1.8 \mathrm{~A} / \mathrm{cm}^{2}$, while the droop ratio rises from 10 to $60 \%$. Wavelength-dependent efficiency droop behavior has previously been investigated in literature $[11,18,26]$. The Auger recombination, piezoelectric field, and carrier leakage in InGaN green LEDs are claimed as the main mechanisms for such droop behavior. In this study, the wavelength-dependent efficiency droop behavior can be well explained by a reduced effective active region volume.

Figure 3a,b presents QW In content-dependent $\beta$ and carrier density at various current densities. It is worth pointing out that $\beta$ decreases nearly linearly with QW In content. In addition, effective thicknesses for the three InGaN LEDs are noted in the figures. Under a physical well thickness of $3.0 \mathrm{~nm}$, the effective thickness for NUV, blue, and green LEDs is estimated to be only 2.07, 1.29, and $0.24 \mathrm{~nm}$ respectively. Our extracted effective thickness of InGaN blue LEDs is consistent with a value of $1.0 \mathrm{~nm}$, as reported by Shen et al., suggesting accuracy in our calculation [1]. Such a significantly reduced effective active region volume is ascribed to inhomogeneous carrier distributions in localized centers, as well as less overlap of electron-hole wave-functions by large piezoelectric fields. The shrink in effective volume of InGaN QW can be evidenced by the experimental confocal micro-photoluminescence [18,20], near-field scanning optical microscopy $[17,27]$, and atom probe tomography [28]. In addition, spatial fluctuations in indium composition have been theoretically modeled to investigate the carrier localization effect [18] and device performance [19]. Moreover, carrier density increases with QW In composition at a given current density, opposite to the trend of $\beta$. For InGaN LEDs with a long emission wavelength, carriers accumulate strongly in the deeply In-rich InGaN clusters by a high degree of localization effect [20,29], leading to a further reduced effective active region volume as well as a larger carrier density. 

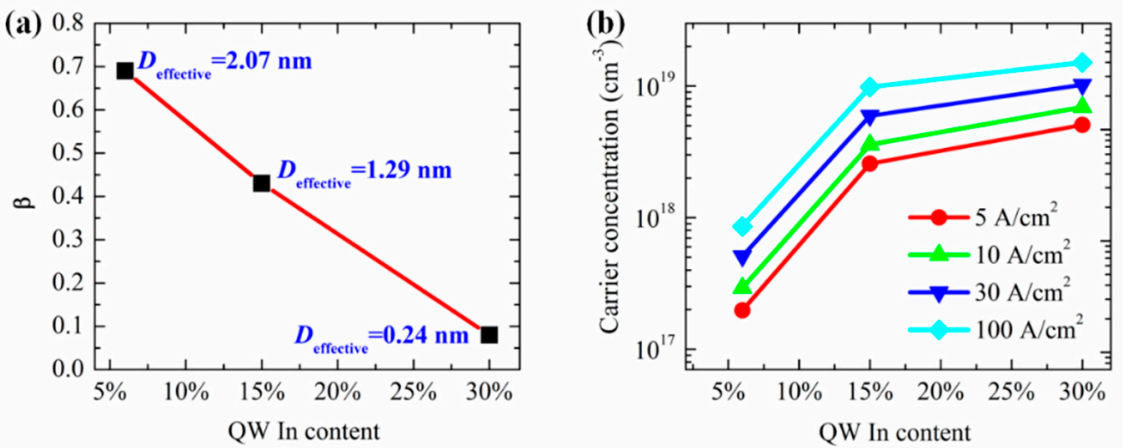

Figure 3. (a) QW In composition-dependent $\beta$ and (b) carrier density at various current densities varied from 5 to $100 \mathrm{~A} / \mathrm{cm}^{2}$.

Figure $4 a-c$ presents the peak wavelength blue-shift and full width at half maximum (FWHM) broadening of emission wavelength with injection current density for the three LEDs. The FWHM broadens from 10 to $30 \mathrm{~nm}$ as the emission wavelength increases from 400 to $525 \mathrm{~nm}$, with a current density varied from 1 to $100 \mathrm{~A} / \mathrm{cm}^{2}$. The wider FWHM for InGaN LEDs with a long emission wavelength is attributed to stronger spatial fluctuations of indium composition within the InGaN QW. Since the blue-shift of wavelength, together with the broadening of FWHM, originates from the carrier filling effect of localized states [16,30], the wider and faster increase of FWHM with current for green LEDs indicates a stronger carrier localization effect as compared to NUV and blue LEDs. Therefore, the wavelength-dependent efficiency droop phenomenon in nitride LEDs can be well interpreted in this way: For InGaN QWs with a low average indium composition the localization potential is relatively shallow and the probability of carriers escaping out of the local potential minima is expected to be high, resulting in a relatively larger effective active volume. On the contrary, for high indium content InGaN wells, the indium compositional spatial fluctuation becomes more prominent and carriers are strongly localized at the deep potential minima, leading to a more reduced effective active volume. Then, the corresponding higher carrier density increases the relative contribution of the Auger recombination rate and carrier leakage over radiative recombination rates, resulting in a lower onset-droop current density as well as an aggravation of the efficiency droop.

Figure $5 \mathrm{a}, \mathrm{b}$ shows the simulation results of normalized IQE versus current density with $\beta$ varying from 0.05 to 1.0 and well thickness ranging from 3 to $15 \mathrm{~nm}$. The values of parameters $A, B$, and $C$ were set to be $7 \times 10^{6} \mathrm{~s}^{-1}, 3 \times 10^{-11} \mathrm{~cm}^{3} \mathrm{~s}^{-1}$, and $2 \times 10^{-30} \mathrm{~cm}^{6} \mathrm{~s}^{-1}$ respectively [16]. The IQE droop is obviously alleviated and the onset-droop moves towards high current density through increasing $\beta$ or well thickness, which is due to a reduction of carrier density. This result is consistent with the previous report about maximum quantum efficiency above $200 \mathrm{~A} / \mathrm{cm}^{2}$ with a thick double heterostructure (DH) active region by Gardner et al. [21]. Nevertheless, the growth of a thick InGaN well is challenging for c-plane InGaN LEDs. With a thick well layer, the piezoelectric field strengthens, resulting in a stronger quantum confinement stark effect (QCSE), as well as a lower overlap of electron-hole wave-functions [31]. One of the biggest advantages of InGaN LEDs grown on semi- and non-polar planes is that the polarization-related electric fields can be significantly reduced, whereby thick InGaN wells can be achieved [32,33]. By employing a thick well of $12 \mathrm{~nm}$, InGaN blue LEDs with a high quantum efficiency and low efficiency droop at a high current density of $400 \mathrm{~A} / \mathrm{cm}^{2}$ on a semipolar (20-2-1) plane, this is realized by Pan et al. [32]. These results indicate that manipulating active region volume and carrier density are promising methods to alleviate the efficiency droop. 

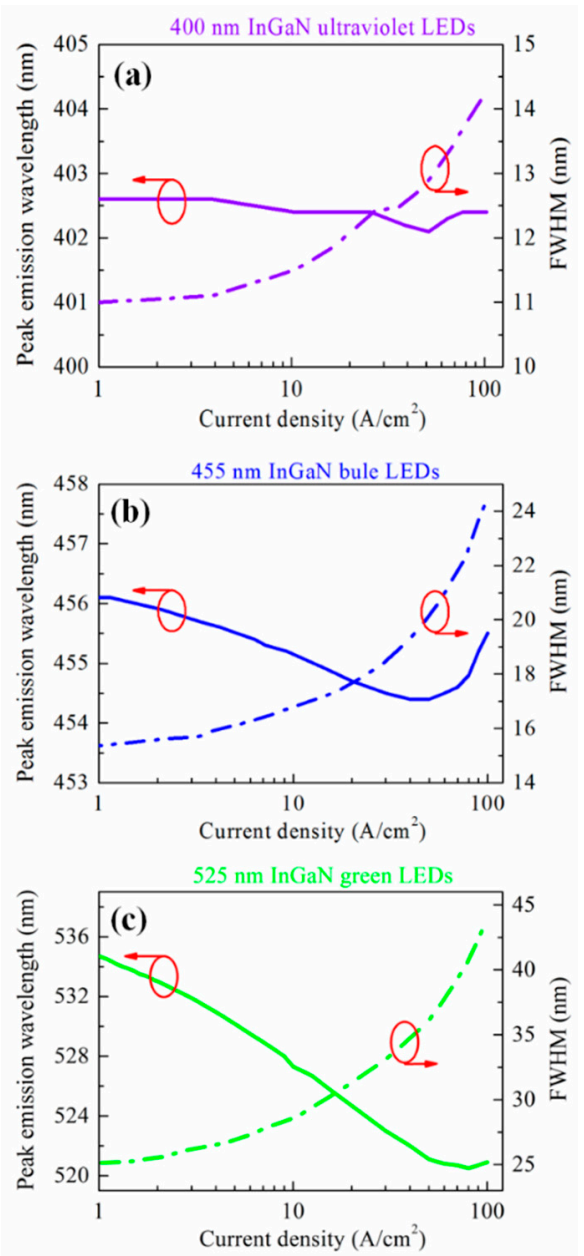

Figure 4. Peak emission wavelength and broadening of full width at half maximum (FWHM) of emission spectrum versus current density for $\operatorname{InGaN~(a)~NUV,~(b)~blue~and~(c)~green~LEDs~respectively.~}$
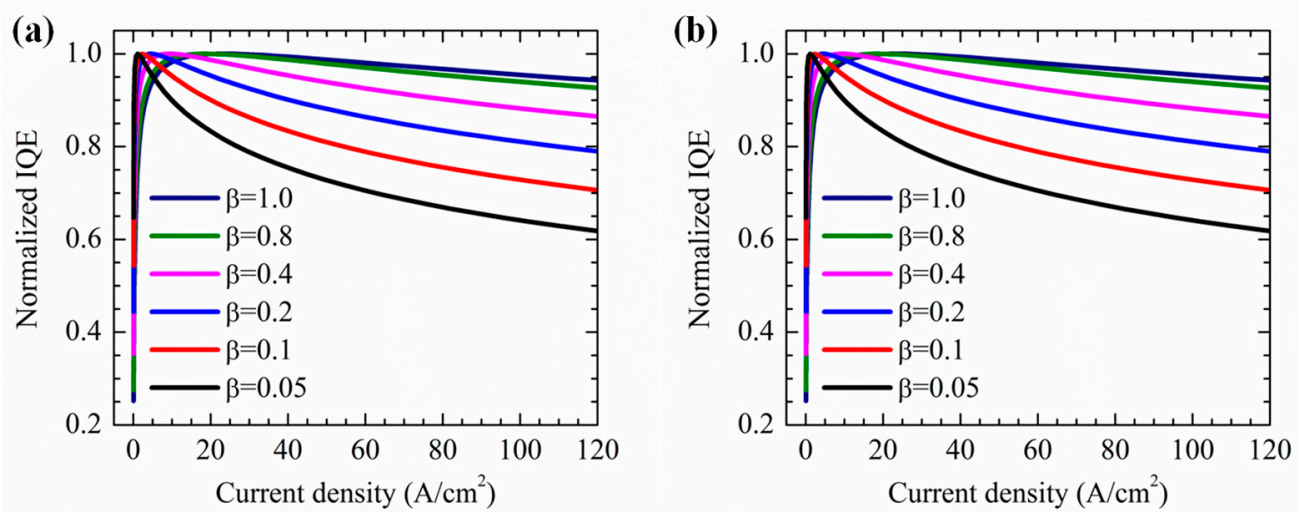

Figure 5. Calculation results of normalized IQE versus current density with (a) $\beta$ varied from 0.05 to 1.0 and (b) well thickness ranged from 3 to $15 \mathrm{~nm}$.

\section{Conclusions}

In conclusion, wavelength-dependent efficiency droop phenomena in nitride LEDs can be well interpreted by the reduced effective active region volume. The concept of a reduced effective active region volume points out that reducing carrier density at a given current density is a promising way to alleviate the efficiency droop. 
Author Contributions: Conceptualization, X.Y. and H.L.; methodology, P.L. and Y.Z.; investigation, P.L. and Y.Z.; writing-review and editing, H.L.; P.L. and Y.Z. contributed equally to this work.

Funding: This research was funded by National Key R\&D Program of China (2017YFB0403100, 2017YFB0403102), Beijing Municipal Science and Technology Project (Z161100002116032), Guangzhou Science \& Technology Project of Guangdong Province, China (201704030106 and 2016201604030035), Innovation Fund Denmark No. 4106-00018B and The Natural Science Foundation of the Jiangsu Higher Education Institutions of China (18KJB510047).

Conflicts of Interest: The authors declare no conflicts of interest.

\section{References}

1. Shen, Y.C.; Müller, G.O.; Watanabe, S.; Gardner, N.F.; Munkholm, A.; Krames, M.R. Auger recombination in InGaN measured by photoluminescence. Appl. Phys. Lett. 2007, 91, 141101. [CrossRef]

2. Delaney, K.T.; Rinke, P.; Van de Walle, C.G. Auger recombination rates in nitrides from first principles. Appl. Phys. Lett. 2009, 94, 191109. [CrossRef]

3. Iveland, J.; Martinelli, L.; Peretti, J.; Speck, J.S.; Weisbuch, C. Direct Measurement of Auger Electrons Emitted from a Semiconductor Light-Emitting Diode under Electrical Injection: Identification of the Dominant Mechanism for Efficiency Droop. Phys. Rev. Lett. 2013, 110, 177406. [CrossRef] [PubMed]

4. Schubert, M.F.; Chhajed, S.; Kim, J.K.; Schubert, E.F.; Koleske, D.D.; Crawford, M.H.; Lee, S.R.; Fischer, A.J.; Thaler, G.; Banas, M.A. Effect of dislocation density on efficiency droop in light-emitting diodes. Appl. Phys. Lett. 2007, 91, 231114. [CrossRef]

5. Piprek, J.; Li, S. Electron leakage effects on GaN-based light-emitting diodes. Appl. Phys. Lett. 2010, 42, 89-95. [CrossRef]

6. Xie, J.; Ni, X.F.; Fan, Q.; Shimada, R.; Özgür, Ü.; Morkoc, H. On the efficiency droop in InGaN multiple quantum well blue light emitting diodes and its reduction with -doped quantum well barriers. Appl. Phys. Lett. 2008, 93, 121107. [CrossRef]

7. Li, H.; Kang, J.; Li, P.; Ma, J.; Wang, H.; Liang, M.; Li, Z.; Li, J.; Yi, X.; Wang, G. Enhanced performance of GaN based light-emitting diodes with a low temperature p-GaN hole injection layer. Appl. Phys. Lett. 2013, 102, 011105. [CrossRef]

8. Zhang, Z.-H.; Ju, Z.G.; Tan, S.T.; Kyaw, Z.; Liu, W.; Ji, Y.; Zhang, X.L.; Hasanov, N.; Sun, X.W.; Demir, H.V. Improving hole injection efficiency by manipulating the hole transport mechanism through p-type electron blocking layer engineering. Opt. Lett. 2014, 39, 2483. [CrossRef] [PubMed]

9. Yang, Y.; Cao, X.A.; Yan, C.H. Rapid efficiency roll-off in high-quality green light-emitting diodes on freestanding GaN substrates. Appl. Phys. Lett. 2009, 94, 041117. [CrossRef]

10. Shin, D.S.; Han, D.P.; Oh, J.Y.; Shim, J.I. Study of droop phenomena in InGaN-based blue and green light-emitting diodes by temperature-dependent electroluminescence. Appl. Phys. Lett. 2012, 100, 153506. [CrossRef]

11. Dai, Q.; Shan, Q.F.; Cho, J.H.; Schubert, E.F.; Crawford, M.H.; Koleske, D.D.; Kim, M.H.; Park, Y.J. On the symmetry of efficiency-versus-carrier-concentration curves in GaInN/GaN light-emitting diodes and relation to droop-causing mechanisms. Appl. Phys. Lett. 2011, 98, 033506. [CrossRef]

12. Laubsch, A.; Sabathil, M.; Bergbauer, W.; Strassburg, M.; Lugauer, H.; Peter, M.; Lutgen, S.; Linder, N.; Streubel, K.; Hader, J.; et al. On the origin of IQE-'droop'in InGaN LEDs. Phys. Status Solidi C 2009, 6, S913-S916. [CrossRef]

13. Verzellesi, G.; Saguatti, D.; Meneghini, M.; Bertazzi, F.; Goano, M.; Meneghesso, G.; Zanoni, E. Efficiency droop in InGaN/GaN blue light-emitting diodes: Physical mechanisms and remedies. J. Appl. Phys. 2013, 114, 071101. [CrossRef]

14. Karpov, S. ABC-model for interpretation of internal quantum efficiency and its droop in III-nitride LEDs: A review. Opt. Quantum Electron. 2015, 47, 1293-1303. [CrossRef]

15. Li, H.; Li, P.; Kang, J.; Li, Z.; Zhang, Y.; Liang, M.; Li, Z.; Li, J.; Yi, X.; Wang, G. Analysis model for efficiency droop of InGaN light-emitting diodes based on reduced effective volume of active region by carrier localization. Appl. Phys. Express 2013, 6, 092101. [CrossRef]

16. Jeong, H.; Jeong, H.J.; Min Oh, H.; Hong, C.-H.; Suh, E.-K.; Leronde, G. Carrier localization in In-rich InGaN/GaN multiple quantum wells for green light-emitting diodes. Sci. Rep. 2015, 5, 9373. [CrossRef] [PubMed] 
17. Watson-Parris, D.; Godfrey, M.J.; Dawson, P.; Oliver, R.A.; Galtrey, M.J.; Kappers, M.J.; Humphreys, C.J. Carrier localization mechanisms in InGaN/GaN quantum wells. Phys. Rev. B 2011, 83, 115321. [CrossRef]

18. Yang, T.-J.; Shivaraman, R.; Speck, J.S.; Wu, Y.-R. The influence of random indium alloy fluctuations in indium gallium nitride quantum wells on the device behavior. J. Appl. Phys. 2014, 116, 113104. [CrossRef]

19. Okamoto, K.; Kaneta, A.; Kawakami, Y.; Fujita, S.; Choi, J.; Terazima, M.; Mukai, T. Confocal microphotoluminescence of InGaN-based light-emitting diodes. J. Appl. Phys. 2005, 98, 064503. [CrossRef]

20. Gardner, N.F.; Müller, G.O.; Shen, Y.C.; Chen, G.; Watanabe, S.; Göez, W.; Krames, M.R. Blue-emitting InGaN-GaN double-heterostructure light-emitting diodes reaching maximum quantum efficiency above. Appl. Phys. Lett. 2007, 91, 243506. [CrossRef]

21. Ryu, H.Y.; Shin, D.S.; Shim, J.I. Analysis of efficiency droop in nitride light-emitting diodes by the reduced effective volume of InGaN active material. Appl. Phys. Lett. 2012, 100, 131109. [CrossRef]

22. Li, P.; Li, H.; Wang, L.; Yi, X.; Wang, G. High Quantum Efficiency and Low Droop of 400-nm InGaN Near-ultraviolet light-emitting diodes through suppressed leakage current. IEEE J. Quantum Electron. 2015, 51, 3300605. [CrossRef]

23. Dai, Q.; Shan, Q.; Wang, J.; Chhajed, S.; Cho, J.; Schubert, E.F.; Crawford, M.H.; Koleske, D.D.; Kim, M.-H.; Park, Y. Carrier recombination mechanisms and efficiency droop in GaInN/GaN light-emitting diodes. Appl. Phys. Lett. 2010, 97, 133507. [CrossRef]

24. Ryu, H.Y.; Shim, J.I. Effect of current spreading on the efficiency droop of InGaN light-emitting diodes. Opt. Express 2011, 19, 2886-2894. [CrossRef] [PubMed]

25. Kioupakis, E.; Rinke, P.; Delaney, K.T.; Van de Walle, C.G. Indirect Auger recombination as a cause of efficiency droop in nitride light-emitting diodes. Appl. Phys. Lett. 2011, 98, 161107. [CrossRef]

26. Chen, J.R.; Wu, Y.C.; Ling, S.C.; Ko, T.S.; Lu, T.C.; Kuo, H.C.; Kuo, Y.K.; Wang, S.C. Investigation of wavelength-dependent efficiency droop in InGaN light-emitting diodes. Appl. Phys. B 2010, 98, 779-789. [CrossRef]

27. Kaneta, A.; Funato, M.; Kawakami, Y. Nanoscopic recombination processes in InGaN/GaN quantum wells emitting violet, blue, and green spectra. Phys. Rev. B 2008, 78, 125317. [CrossRef]

28. Li, H.; Khoury, M.; Bonef, B.; Alhassan, A.I.; Mughal, A.J.; Azimah, E.; De Mierry, P.; Nakamura, S.; Speck, J.S.; DenBaars, S.P. Efficient Semipolar (11-22) $550 \mathrm{~nm}$ Yellow/Green InGaN Light-Emitting Diodes on Low Defect Density (11-22) GaN/Sapphire Templates. ACS Appl. Mater. Interfaces 2017, 9, 36417. [CrossRef] [PubMed]

29. Li, P.; Li, H.; Li, Z.; Kang, J.; Yi, X.; Li, J.; Wang, G. Strong carrier localization effect in carrier dynamics of 585 nm InGaN amber light-emitting diodes. J. Appl. Phys. 2015, 117, 073101. [CrossRef]

30. Lee, Y.J.; Chiu, C.H.; Ke, C.C.; Lin, P.C.; Lu, T.C.; Kuo, H.C.; Wang, S.C. Study of the excitation power dependent internal quantum efficiency in InGaN/GaN LEDs grown on patterned sapphire substrate. IEEE J. Sel. Top. Quantum Electron. 2009, 15, 1137-1143.

31. Ryou, J.-H.; Douglas Yoder, P.; Liu, J.; Lochner, Z.; Kim, H.; Choi, S.; Kim, H.J.; Dupuis, R.D. Control of quantum-confined stark effect in InGaN-based quantum wells. IEEE J. Sel. Top. Quantum Electron. 2009, 15, 1080-1091. [CrossRef]

32. Pan, C.-C.; Tanaka, S.; Wu, F.; Zhao, Y.; Speck, J.S.; Nakamura, S.; DenBaars, S.P.; Feezell, D. High-power, low-efficiency-droop semipolar (2021) single-quantum-well blue light-emitting diodes. Appl. Phys. Express 2012, 5, 062103. [CrossRef]

33. Ling, S.-C.; Lu, T.-C.; Chang, S.-P.; Chen, J.-R.; Kuo, H.-C.; Wang, S.-C. Low efficiency droop in blue-green m-plane InGaN/GaN light emitting diodes. Appl. Phys. Lett. 2010, 96, 231101. [CrossRef]

(C) 2018 by the authors. Licensee MDPI, Basel, Switzerland. This article is an open access article distributed under the terms and conditions of the Creative Commons Attribution (CC BY) license (http://creativecommons.org/licenses/by/4.0/). 